\title{
Transfer of interitem associations from serial to paired-associate learning'
}

WAYHE L. MARTIN ${ }^{2}$ AND WILLIAM A. GREENE

EASTERN WASHINGTON STATE COLLEGE

Transfer of interitem associations from a serial to a pairedassociate (PA) list was investigated. Two serial and two DA lists were used. All lists were constructed from consonant-vowel-consonant trigrams matched for meaningfulness and arranged so as to minimize intralist variability. In the experimental condition $S$ learned a PA list constructed from adjacent items on a previously learned serial list. In the control condition the irrelevant PA list was learned. No differences in trials to learn the two PA lists were found. The results of the present experiment replicate previous transfer studies in which such lists were constructed of adjectives. An interitem association theory of serial learning is not supported.

To clarify the nature of the effective stimulus in serial learning, Horowitz \& Izawa (1963) investigated transfer from serial to PA learning when the transfer measure was based on a comparison between two groups. The first group learned a serial list followed by a PA list. Ss in the second group learned only the PA list. Horowitz and Izawa obtained positive transfer from serial to PA lists. However, the measure of transfer was based on a comparison of a group which had previously learned a serial list with one which had had no previous experience. As Young \& Casey (1964) point out, the results of Horowitz and Izawa may be either a function of interitem associations formed during previous serial learning, or they may simply reflect a differential practice effect which would, of course, confound any interpretation of the results.

Young $(1961,1962)$ and Young \& Casey (1964) have found that PA learning following relevant serial learning does not differ from PA learning following irrelevant serial learning. A relevant PA list was defined as constructed from adjacent items on the previously learned serial list. An irrelevant PA list was defined as having been constructed from a serial list with which S had had no previous experience. The lists used in these experiments were made up of adjectives. In Young \& Casey's (1964) study the adjectives were taken from the condition of the Horowitz \& Izawa (1963) experiment which yielded the greatest positive transfer. Although in all these experiments the intralist similarity and similarity between sets of lists were held as low as possible, adjectives may have a considerably different association value and meaning for individual Ss. This difference of association value may produce inconsistent intralist variability.

The present experiment has attempted to reduce this source of intralist variation by using $\mathrm{CVCs}$ having approximately equal value on Noble's (1961) meaningfulness scale.

Method

Twenty Ss, 10 in each of two conditions, participated in the experiment. Although 26 Ss were tested, six Ss failed to reach criterion in PA learning. Of these six Ss, three had been assigned to relevant PA learning and three had been assigned to irrelevant PA learning. All Ss were students enrolled in an introductory psychology course at Eastern Washington State College and had been awarded 10 points for participation in the experiment. None of the Ss had had previous experience in verbal learning experiments.

Twenty syllables were selected from Noble's (1961) list of CVCs. The syllables ranged from 2.02 to 2.19 on Noble's meaningfulness $\left(m^{\prime}\right)$ scale. Two serial lists containing 10 syllables each were constructed following the conventional rules set by Hilgard (1951). Each list had an approximately equal distribution of scale valued syllables. An asterisk placed before the first syllable of each list served as the anticipation signal. Two nine-pair PA lists composed of adjacent items on the respective serial lists were used in PA learning. A Lafayette memory drum was used to present the lists.

This experiment consisted of two phases: a serial learning phase, and a PA learning phase. In the serial learning phase, each $S$ was required to learn one of two 10-item serial lists to a criterion of one perfect trial. In the PA learning phase, each $S$ was required to learn either a relevant or irrelevant PA list.

The design of this experiment was a 2 by 2 factorial. In the first phase, Ss were randomly given one of two serial lists. In the second phase, Ss were again given one of the two PA lists. This design reduces to two basic conditions; half the Ss were exposed to a PA list after relevant serial learning and the other half were exposed to a PA list after irrelevant serial learning.

The PA lists had been constructed from adjacent syllables on the respective serial lists. That is, items $A, B$, and $C$ of the serial lists were combined to form PA items A-B and B-C. This process was continued throughout each serial list until each item, except the first and last, were used as both a stimulus and a response in the PA list. The first item, of course, acted only as a stimulus and the lastitem acted only as a response. The order of the pairs in the list was changed from trial to trial.

All lists were learned by the anticipation method to a criterion of one perfect trial. Approximately $3 \mathrm{~min}$. 
separated the learning of the serial and PA lists to permit giving PA instructions. An exposure time of 2 sec. and an intertrial interval of 6 sec. was used in the presentation of both the serial and PA lists.

The $\mathrm{E}$ has found through previous experience that continuation beyond approximately 57 trials results in severe $S$ fatigue. Therefore, if an $S$ had not learned the PA list within 57 trials he/she was rejected. Results

The means and standard deviations of trials to criterion for each serial list were: SL1, $M=21.9$, $\mathrm{SD}=8.10$; and $\mathrm{SL} 2, \mathrm{M}=22.2, \mathrm{SD}=7.77$. As can be seen, the two serial lists may be considered to be of equivalent difficulty and homogenity of variance can be assumed.

The means and standard deviations of trials to criterion for relevant and irrelevant PA learning were: Relevant PA, $\mathrm{M}=24.4, \mathrm{SD}=13.58$; Irrelevant $\mathrm{PA}$, $\mathrm{M}=28.1, \mathrm{SD}=11.94$. Although no significant differences were found, the differences between the means was in the direction predicted by an S-R chaining (i.e. interitem association) hypothesis.

Learning of individual items on the PA lists as a function of serial position on the relevant serial list was also analyzed. No serial position effect was found to exist.

\section{Discussion}

The results of the present study do not support a theory of positive transfer of interitem associations from serial to PA learning. They do replicate the results of previous investigations by Young (1961,
1962) and Young \& Casey (1964) and lend further support to Young and Casey's contention that the positive transfer observed by Horowitz \& Izawa (1963) was due to practice effects.

Apparently CVCs matched for meaningfulness are equivalent to adjectives as used for this task by Young (1961, 1962) and Young \& Casey (1964). Either the hypothesized intralist variation does not exist in the Young and Young and Casey studies, or the effects of it have been eliminated by randomization.

\section{References}

Hilgard, E. R. Methods and procedures in the study of learning. In S. S. Stevens (Ed.), Handbook of experimental psychology. New York: Wiley, 1951. Pp. 517-567.

Horowitz, L. M., \& lzawa, C. Comparison of serial and pairedassociate learning. J. exp. Psychol., 1963, 65, 352-361.

Noble, C. E. Measurements of association value $(a)$, rated associtions $\left(a^{*}\right)$, and scaled meaningfulness $\left(m^{\circ}\right)$ for the $2100 \mathrm{CVC}$ combinations of the English alphabet. Psychol. Rep., 1961, 8, 487521.

Young, R. K. The stimulus in serial verbal learning. Amer. J. Psychol., 1961, 74, 517-528.

Young, R. K. Tests of three hypotheses about the effective stimulus in serial learning. $J$. exp. Psychol., 1962, 63, 307-313.

Young, R. K., \& Casey, M. Transfer from serial to paired-associate learning. J. exp. Psychol., 1964, 67, 594-595.

\section{Nates}

1. This report is based on a paper read at the Fifty-first Annual Meeting of the Kentucky Academy of Science, University of Kentucky, 1965.

2. Now at the Wenner-Gren Aeronautical Research Lab. University of Kentucky, Lexington, Kentucky. 